\title{
Use of budget- and process-based planning in the course of nuclear power plant units construction
}

\author{
Oksana Kurakova ${ }^{1, *}$ \\ ${ }^{1}$ Moscow State University of Civil Engineering, 129337, Yaroslavskoye Shosse, 26, Moscow, Russia
}

\begin{abstract}
This paper deals with approaches to planning and management of development projects in the area of construction, specifically construction of nuclear power plant units, using the tools of the processbased budgeting model. The author considered development project processes, linked them to processes of nuclear power plant units construction and developed a business model of a group of companies, which implements these projects.
\end{abstract}

\section{Introduction}

The purpose of this paper is to develop efficient tools for a large construction company to plan construction processes using the model of process-based budgeting.

Project budgeting models are widely used throughout the world. A lot of papers relating to this subject were written. $[1,2,3]$

Economic literature offers to use the following two definitions: a budget process and budget management. The methodology that allows to define maximum financial indicators according to the predetermined scheme and presupposes non-exceedance of these indicators in the course of its implementation is called a budget process. Budget management (management by differences, budget planning) represents a three-stage method of organizational assets management that includes the following:

- Plan determination (budget).

- Determination of actual indicators.

- Determination of differences and analysis of their reasons as well as making decisions based on the analysis results.

A conventional approach to budget planning presupposes reproduction of the format of reports executed by different departments. Such reports represent cumulative information about resources to be acquired and sales proceeds. In case of monthly analysis of the results of project implementation, actual data within the reporting period is compared to budget figures and differences are determined. As a rule, these reports are exclusively financial. This model is used by most Russian enterprises.

\footnotetext{
* Corresponding author: ks-home@mail.ru
} 
In today's context, under conditions of dynamic production and competitive struggle, conventional budgeting does not always allows to get the expected result. The reason for that is in the fact that initially the function of budgets was to direct managers' consciousness towards protection of shareholders' funds and warrant that managers are anxious about cost control. [1] In the course of time, budgets started to be used for the purposes of "management by figures". They turned to be agreements with preset performance results that force managers of all levels to be responsible for the achievement of certain financial results, even if many variables that determine these results were uncontrolled. [6] Direct and variable costs for regular labor force and material costs prevailed in the structure of costs of an organization earlier. Conventional budgeting could satisfy all management needs. Operation of a modern company is associated with considerable costs for project management. Such activities as marketing, customer service, real estate construction, and manufacturing research are referred to them.

It is required to create and implement another budgeting method for the purposes of keeping up with other companies, which evaluates the effectiveness of all processes related to project implementation. The new method of planning, control and cost containment is called process-based budgeting or activity-based budgeting (ABB). [2]

Activity-based budgeting was described by Robert S. Kaplan, an American economist, and Robin Cooper, an American economist, as a process that is reverse to the method of activity-based costing ( $\mathrm{ABC}$ in reverse). There are different definitions of activity-based budgeting (ABB): process budgeting, functional budgeting, budgeting based on activities, and budgeting based on actions. [4]

However, each area of activity brings in its own peculiarities when developing a budget model. It is associated with differences in processes of companies' operation, in their organizational structure and in-house functional relations. An attempt to develop a model of planning the company's activity using the process-based system of budgeting as exemplified by a large development company is the basis for this paper. This model should be based on processes carried out in the course of development project implementation. A development project has the following stages:

- Concept design stage (CDS): at this stage the real estate market is analyzed, a real estate item is selected, a project strategy is developed, an investment analysis is carried out, preliminary permissions are executed and investment and loan funds are raised.

- Design stage (DS): this stage is included into the development of a financial scheme (fund raising), an architectural and engineering team is gathered, a broker is hired to give advice and sell facilities, design management is implemented and a tender for construction works is held.

- Construction stage (CS): at this stage construction and installation works are carried out, i.e. construction coordination (delivery of materials to the site, engineering works, etc.).

- Implementation stage (IS): this stage includes marketing, sale of facilities as well as supervision of buildings upkeep and utility systems operation after construction completion.

From the point of view of the order of property development projects implementation, the stages of a development process can be presented as follows (see Fig.1). 


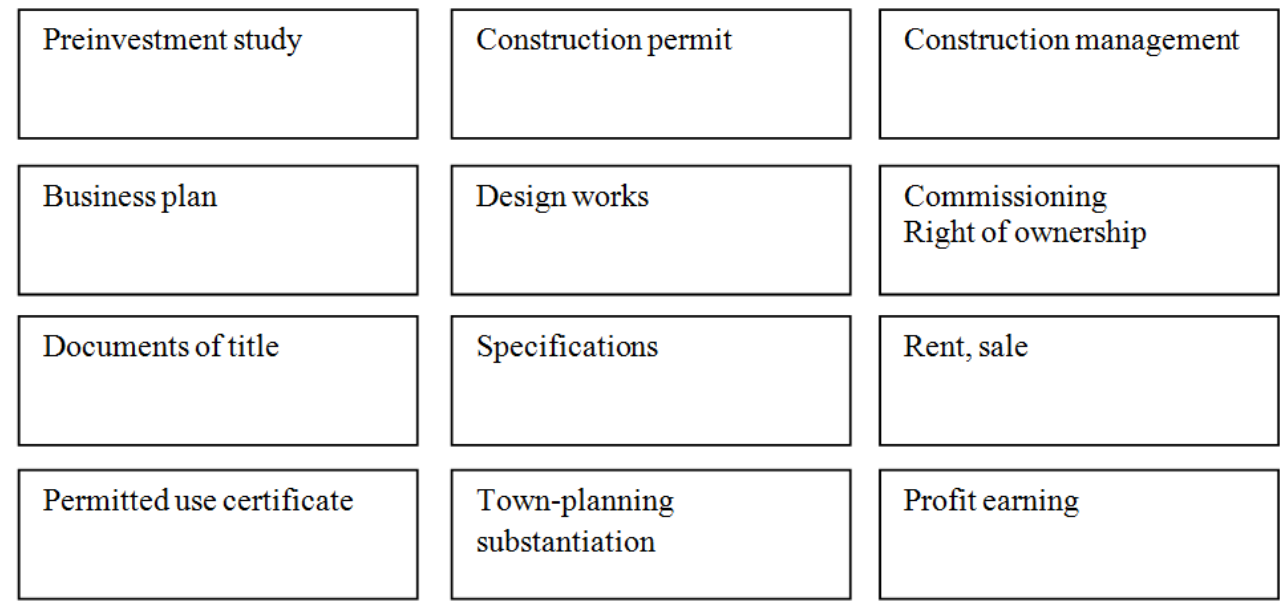

Fig. 1 Stages of a development process.

It should be remembered that a project is destined for inefficiency (i.e. there's a high risk of failure to achieve the objectives or the objectives will be achieved with heavy spending), if the company uses the process-based approach for project management, and at the same time management of the rest of its activities that have an impact on project implementation is carried out on the basis of, for example, the top-down approach. So, when choosing an approach to project management, a company should consider its method of in-house organizational management (business management model), and this method should comply with the selected approach to project management. Therefore, when choosing the process-based approach to development projects management, a company should use the model of interrelated business processes to control the rest of its activities having an impact on the achievement of the objectives of these projects.

\section{Methodology}

The methodological framework of this research is represented by generally accepted scientific methods and techniques that provide for comprehensiveness, consistency and validity of research results, including methods of scientific analysis and synthesis, grouping, comparison and generalization, and literature review. A qualitative analysis, an economic analysis, modeling of development project processes and methodological approaches to the formation of a budget model of a development company that implements the project for the construction of a nuclear power plant on the basis of the main processes were also used in this paper.

It is required to determine activities for the creation of that or another cost object for the purposes of process-based budgeting in the course of implementation of a development project. Usually there are four types of actions:

- Basic actions aimed at manufacturing (rendering of services) (hereinafter as applied to a development project - construction), are of value to the customer and ensure acquisition of income for the organization (sale, manufacturing, delivery, etc.).

- Support actions designed to carry out the basic actions (IT support, personnel record keeping, procurement, etc.).

- Management actions that cover the entire set of management functions at the level of each business process (general management, personnel management, and sales management). 
- Development actions aimed at improvement of construction processes, a real estate item under construction, technologies and equipment (research work).

Drivers that calculate the duration (number) of actions are an obligatory component of ABB. After that, demand in resources used for carrying out all planned actions as well as costs for the provision of the required amount of resources with work are calculated. A costs driver is a meter that shows how many times the process was repeated (reversed) or used for another process.

The final stage of $\mathrm{ABB}$ is grouping of cost items by financial responsibility centers (FRC) or business processes.

There is a good reason to consider $\mathrm{ABB}$ as the next step after the introduction of the activity-based costing method (hereinafter referred to as $A B C$ ), since it is inefficient to create a budgeting system in a company that is based on actions after the introduction of $\mathrm{ABC}$, in which models of business processes are created and adjusted as well as parameters of distribution of the cost of resources and activities (Fig. 4). In addition, when introducing $\mathrm{ABB}$ it is required to use software tools that, on the one hand, allow to reduce labor intensity greatly and, on the other hand, increase flexibility of system application under conditions of permanent changes. Nevertheless, the ABB method can be used with no need to introduce $\mathrm{ABC}$ first.

Budget simulation by processes allows to get various data quickly and that is required for efficient project management.

The algorithm of this model is as follows: first, one should analyze industry specifics, business processes of the company that implements a development project and after that create a model of these business processes. Then data on the development project are studied for the purposes of further modeling of business processes (if a standard development project is implemented, let's say, construction of a dwelling house or something like that, one can use a standard model of business processes; if the project presupposes certain industry specifics, one should use a referential model of business processes).

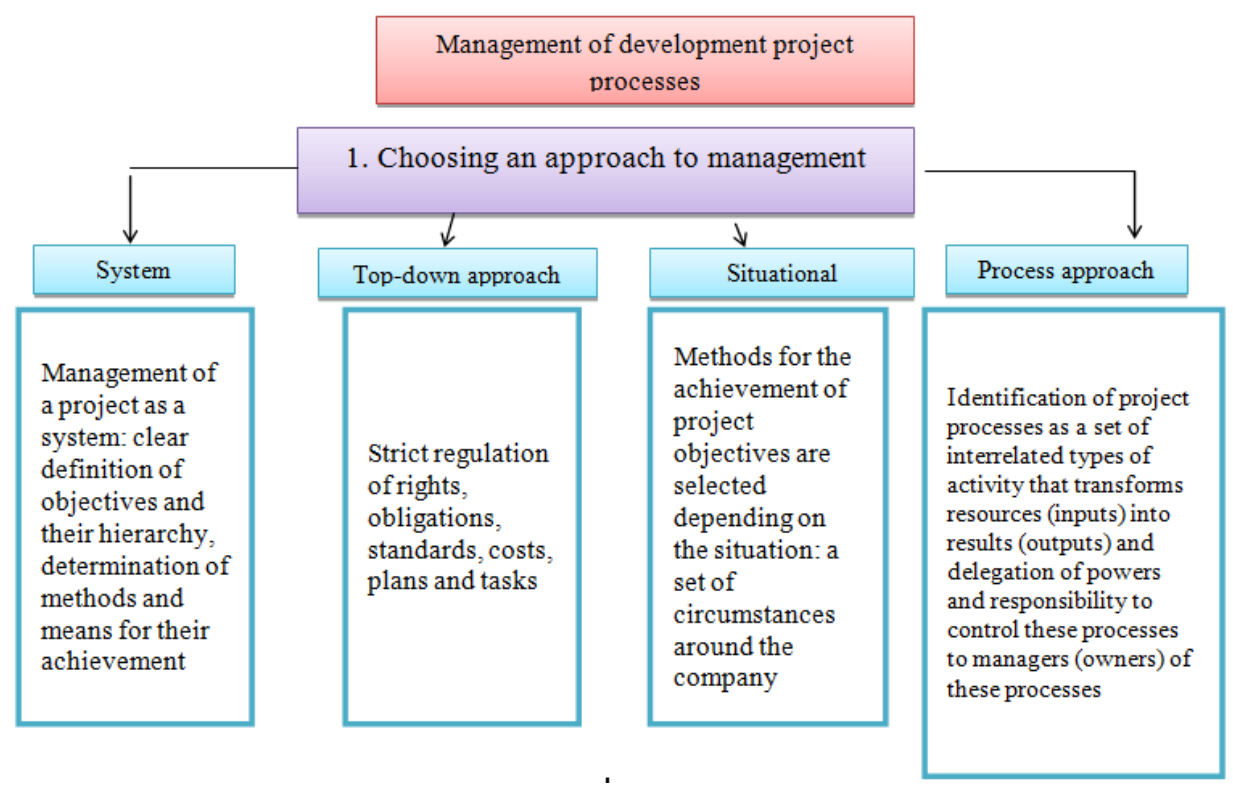

a) 


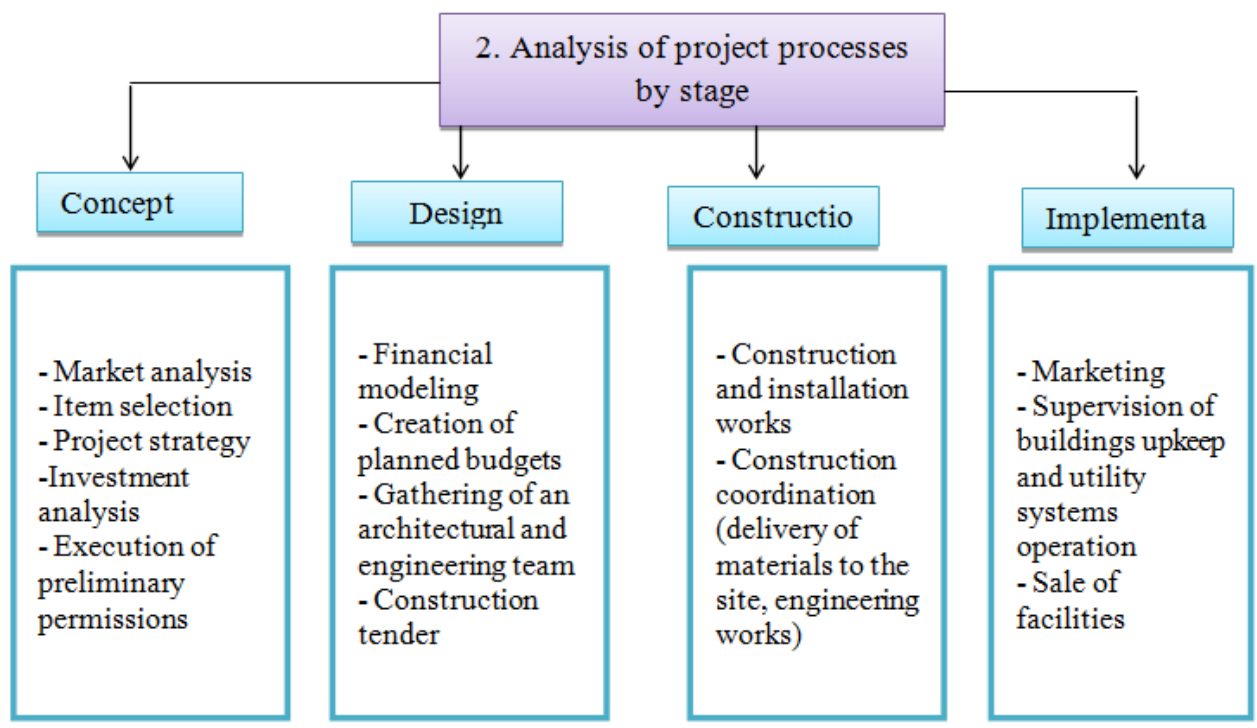

b)

3. Choosing a budgeting model

" Based on an in-depth analysis of cause-andeffect relationships;

determines the

efficiency of each

process; one can see

which processes are

less efficient in the

course of

implementation of that

or another project;

commitment to the

results by means of

cost control and cost

minimization.

“_"

Heavy activity content

because the $\mathrm{ABC}$

modelis in its basis.

\section{. Choosing a budgeting model}

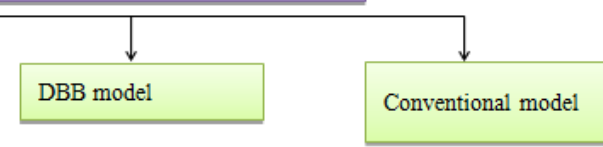

"_,"

Lack of a strict planning flow; one can use only the drivers that can be calculated;

presupposes frequency

increase, reduction of

the level of detail and

costs analysis, more

users are covered.

"."

Little available

information;

insufficient

experience;

complexity of

implementation in

practice.

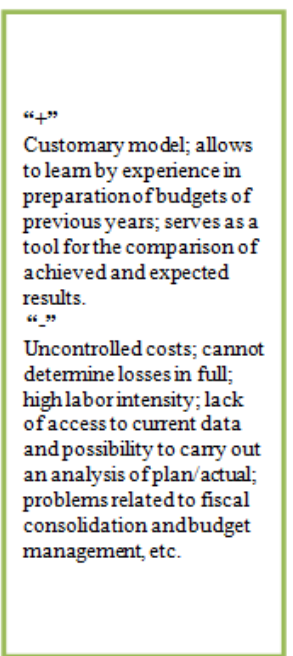

c) 


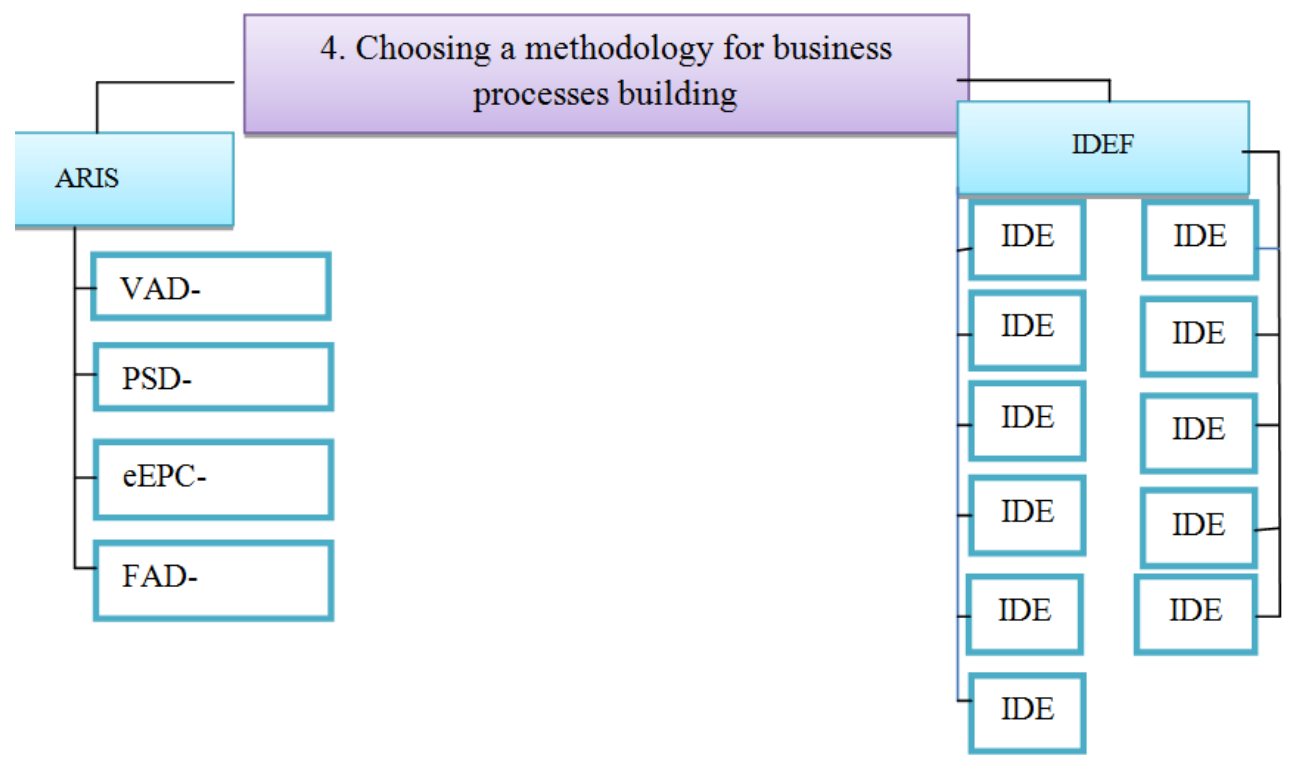

d)

Fig. 2 (a, b, c, d) Algorithm of development project processes management

After creation of a business processes model one should determine which processes can run simultaneously (e.g., some strategic processes) and which ones can run one after another. In practice, to reduce the construction period, many processes like study of financiability and development of a declaration of intent (DOI) are started simultaneously. When the model of business processes is developed, the quantity of material resources, workers, machinery for each process is calculated and planned budgets are developed.

Conclusion: use of the process-based model in project management allows to optimize work and ensure that in the course of project implementation only those processes will be engaged that are really needed and sufficient for the achievement of project objectives. This approach allows to save resources and, consequently, reduce costs for the implementation of each individual project.

\section{Results}

For the successful application of this model it is required to:

1) Set the objectives that should be achieved by means of implementation of a development project.

2) Describe the activity relating to the implementation of a development project by means of creation of a system of interrelated processes aimed at objectives achievement; determine the conditions for management of this system and responsibility.

3) Determine managed conditions for each process (thresholds, inputs, outputs, objectives, required regulatory requirements for the implementation, performance indicators, methods for performance monitoring and evaluation, responsibility).

4) Develop budgets for each process that will allow to identify the scope of required and sufficient costs for its implementation after exclusion of inexpedient costs and costs that do not have an impact on the achievement of process objectives.

5) Determine the adequacy of using the standard model of processes of a development project that consists of top-level processes (lumped processes aimed at achieving project 
objectives) and the need for their decomposition; in case of decomposition - to set its level, i.e. the level of detail of each decomposed process.

6) Carry out decomposition of processes (splitting into smaller sub-processes), for the effective implementation of which a more detailed description is required.

This model was used by the example of XXX JSC. The developed business model is shown in Fig. 3.
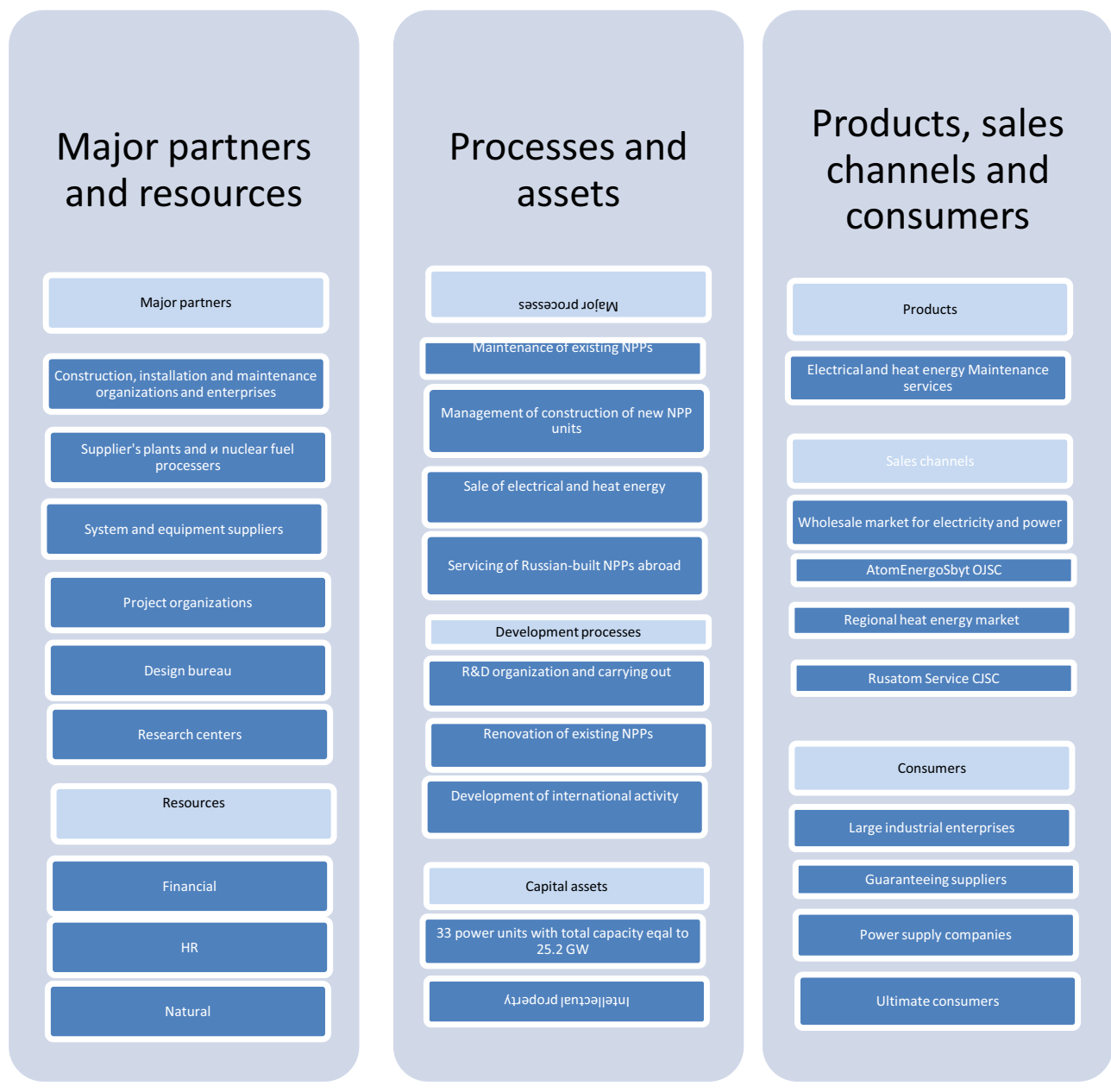

Fig. 3. Business model of XXX JSC that underlies process-based budgeting of development projects management.

As a result of its activity the group of companies creates a positive cash flow that is transformed into dividends for shareholders and proprietary investments channeled to development. Construction of a nuclear power plant represents a certain project portfolio that includes projects for the construction of individual power units. These projects can be implemented either simultaneously or one by one. Activities related to the management of development projects for the construction of a nuclear power plant and individual power units represents a referential model that takes into account the specifics of nuclear facilities 
construction. It should be noted that the use of the process-based approach allows both to control costs by each process of a development project for the construction of nuclear power plant units and to control them as opposed to estimated budget planning or accounting planning that in turn do not allow to determine which costs and in what amounts were spent for that or another project process and show just total costs for the project as a whole. Use of this approach allows to consider all costs for processes during planning, even if the same sub-process is repeated, one can calculate how many resources will be required for its implementation, and in case of the conventional approach, it turns out that either we spend more resources or we have insufficient resources, since we cannot see the entire chain of processes.

\section{Conclusions}

The proposed model allows to control costs efficiently. Implementation of this model has a beneficial effect in case of using up-to-date databases with OLAP technologies. The use of process-based budgeting allows to determine the prime cost of each process both at the enterprise and from the point of view of management of a development project with the required level of detail, create the structure of costs for processes, track expenditure items of a certain financial responsibility center and use supplementary measurements to add more flexibility to the budget structure.

As compared to conventional control of costs, the process-based approach expands the range of implemented tasks, including studying of reasons for deviations of the level of costs from standards, identification of factors of deviations of actual costs from the planned level, determination of the level of expedience of available processes characteristics restoration up to the standard level by means of comparison of internal and external losses incurred by incompliance with costs for the assurance of the company's products quality compliance with the requirements of the selected quality degree. Process-based budgeting meets the objectives of quality management to a greater extent than conventional management aimed at cost saving that can result in the fact that the company will lose its positions at the market over the long term.

One of the obstacles relating to today's widespread acceptance of cost budgeting as a management technique is detachment of conventional accounting from managers' information needs and time required to apply this method. The problem becomes irrelevant in the context of expansion of possibilities allowing to make many accounting and analysis functions automatic. Modern software products designed for cost control automation allow to track the dynamics of dependence of prices for products, the volume of output and the volume of sales on a range of processes related to financial and operational activities and changes in market conditions as well as basic processes of costs dependent on them. On the other hand, a clear definition of the above mentioned requirements both for products and services of a certain quality degree and for the processes ensuring this quality facilitates it.

The new approach lies in the fact that the method of costs calculation used along with process-based budget planning in the light of development project peculiarities is based on determination of process variations due to specific requirements or conditions (peculiarities). Switching to process-based budgeting along with cost calculation based on the peculiarities of a development project helps to solve many problems related to conventional budgeting because it:

- Imposes responsibility for the achievement of planned process indicators and accounting of costs for workers' participation in project implementation.

- Allows to get exact information about the work load and see the reasons for variations (deviations) with respect to which measures should be taken. 
- Allows to estimate the efficiency of a development project from the point of view of the customer's satisfaction with the results of its implementation and evaluation of optimum resource requirements.

\section{References}

1. I.T. Balabanov, Financial analysis and planning of an economic entity. (Finance and statistics, Moscow , 2000)

2. R.R. Gabdullin, Vestnik KGFEI. 2(11), 21-22 (2008)

3. R. S. Kaplan. The strategy-focused organization. How balanced scorecard companies thrive in the new business environment ( Olimp Business, Moscow, 2004)

4. S. Alimoradi, International Business Management ,10 , 1809-1816 ( 2016)

5. A. Afful-Dadzie, E. Afful-Dadzie, I. Awudu, J. K. Banuro, Applied Energy, 188, 71-82 (2017)

6. I. A. Rahman, A. H. Memon, A. T. Abd Karim, Social and Behavioral Sciences, 107, 120-128 (2013)

7. P. Bakhshi, A. Touran, Procedia Engineering, 85, 52-60 (2014)

8. D. Walczak, A. Rutkowska, European Journal of Operational Research, In Press, (2016)

9. M. Buso, F. Marty, P. T. Tran, International Journal of Industrial Organization, In Press, Accepted Manuscript, Available online (2016).

10. S. Sponem, C. Lambert, Management Accounting Research, 30, 47-61 (2016).

11. Boaz Ben-Moshe, Michael Elkin, Lee-Ad Gottlieb, Eran Omri, Theoretical Computer Science, 627, 13-25 (2016).

12. Mikel Zubizarreta, Jesús Cuadrado, Jon Iradi, Harkaitz García, Aimar Orbe, Evaluation and Program Planning, 61, 22-37 (2017).

13. W.C. Kim, R. Mauborgne, Harvard business review, 1-7 (2015)

14. A.P.C.Chan, D.W.M. Chan, Y.H. Chiang, B.S.Tang, E.H.W. Chan, K.S.K. Ho, Journal of Construction Engineering and Management, 130 (2), 188-198 (2004)

15. H. Osman, H. Structure and Infrastructure Engineering, 12 (1), 108-121 (2016)

16. M. J. Lebas, Budgeting and Anticipatory Management, International Encyclopedia of the Social \& Behavioral Sciences (Second Edition), 894-900 (2015)

17. L. Cherchye, T. Demuynck, B. De Rock, Journal of Economic Theory, 152, 224-236 (2014)

18. A.S.O. Ogunjuyigbe, T.R. Ayodele, O.A. Akinola, Applied Energy, 187, 352-366 (2017)

19. Z. Alwan, P. Jones, P. Holgate, Journal of Cleaner Production, 140 ( 1), 349-358 (2017). 